\title{
Cultivar lo propio Entre el hacer y el decir de Rodolfo Franco
}

\author{
Nurturing One's Own \\ Between Saying and Doing in Rodolfo Franco
}

\author{
Germán Casella \\ casellahav@gmail.com \\ Instituto de Historia del Arte \\ Argentino y Americano. Facultad de \\ Bellas Artes. Universidad Nacional de \\ La Plata. Argentina \\ Recibido: 8/10/2018 \\ Aceptado: 11/3/2019
}

\begin{abstract}
Resumen
En esta reseña se presentan los principales aportes de la investigadora Cora Roca para la revalorización de la figura de Rodolfo Franco (1889-1954), considerado el primer escenógrafo argentino. Se propone un recorrido por dos textos de la autora -Rodolfo Franco: el fundador de la escenografía argentina (2016) y Rodolfo Franco: escritos sobre arte y escenografía (2018-) para finalmente delinear un panorama general del ambiente teatral porteño de la época. La lectura de ambos libros resultará complementaria para revisar la labor de Franco como un escenógrafo fundacional ocupado en su práctica en lo nacional, pero combinada con una formación y visión meramente europeas.
\end{abstract}

\section{Palabras clave}

Teatro; escenografía; producción; nacional; fundación

\begin{abstract}
This review presents Cora Roca's main contribution to Rodolfo Franco's personal appreciation, as the first Argentinian scenographer. We analyze two texts written by Roca (Rodolfo Franco: el fundador de la escenografía argentina (2016) [Rodolfo Franco: Founder of Argentinian Scenography] and Rodolfo Franco: escritos sobre arte y escenografía (2018) [Rodolfo Franco: On Art and Scenography]) to reach a general outline of theatre field in Buenos Aires at that period. In reading both texts we will find a complementary stance to look into Franco's work as an essential scenographer devoted to his labour on a national scale woven into a european education and perspective.
\end{abstract}

\section{Keywords}

Theatre; Scenography; Production; National; Foundation 
«Así fui comprendiendo que la misión de la escenografía, no era solamente la de representar de una manera realista o simbolista tal o cual ambiente. Había sido algo más importante: el decorado debía reflejar el justo espíritu de la obra.»

Rodolfo Franco (en Roca, 2016, p. 235)

En el año 1924 la entonces Municipalidad de Buenos Aires toma a su cuidado al Teatro Colón como parte de un plan para transformarlo en un teatro nacional. Desde sus orígenes ha sido un teatro italianizado y concesionado y, a partir de este plan, pasa a manos de una comisión directiva presidida por el arquitecto Martín San Noel. Entre sus proyectos para el Colón, figura la conformación de una orquesta y un cuerpo artístico estable accesible a todos los sectores sociales. Alentado por una amistad gestada en París, Noel convoca a Rodolfo Franco como nuevo director escenográfico. En aquel momento Maestro de Pintura de la posterior Escuela De la Cárcova, Franco acepta y funda el primer taller de escenografía argentina para producir en el país los decorados y los vestuarios de los espectáculos programados. Instala los diversos departamentos necesarios para tal efecto y convoca a artistas argentinos a participar de ellos. A partir de su labor sostenida, comienza la implementación del proyecto de un teatro nacional: promueve la composición de las primeras óperas argentinas, crea y ejecuta más de trescientas escenografías, funda el Taller de Escenografía de la Escuela Superior de Bellas Artes y la carrera de Escenografía que posteriormente pertenecerá a la Universidad Nacional de La Plata. Esta prolífica labor es nucleada y narrada en los libros de Cora Roca Rodolfo Franco: el fundador de la escenografía argentina (2016) y Rodolfo Franco: escritos sobre arte y escenografía (2018), pertenecientes al Instituto Proteatro y editados por Eudeba. En el caso del primero, la autora asume el compromiso de rescatar esta figura nacional, relegada por el paso del tiempo y la ausencia de investigaciones afines. Para hacerlo, Roca realiza una exhaustiva biografía de Franco en tono de narrativa novelada desde la recuperación de notas periodísticas, entrevistas a familiares y escritos del propio escenógrafo. Estos últimos tienen su presentación en el segundo libro, donde la autora no organiza las fuentes por año de publicación, sino por núcleos temáticos y, así, genera una historia tradicional de la escenografía.

La lectura de ambos libros resulta complementaria para delinear el valor y la calidad del trabajo de Rodolfo Franco, ocupado siempre en la promoción de las artes nacionales a la vez que influenciado por los obligados estudios europeos de la 
época. Finalmente, se podrá comprender el trabajo de Franco como inscripto en un marco de producción nacional que, a pesar de fomentar el campo artístico local, está aún condicionado por la formación canónica europea.

\section{Fundador: momentos de una producción nacional}

Cora Roca comienza su libro Rodolfo Franco: el fundador de la escenografía argentina (2016) con una desalentadora postura acerca de la pretendida conservación de la historia nacional: «En muchos pueblos se conservan las raíces del pasado preservando los orígenes de la historia que conforma su cultura. Lamentablemente, en el nuestro sucede lo contrario» (p. 13). Con esto se posiciona en su labor de reconstruir «y de rescatar del olvido a nuestros fundadores, justamente al creador, escenógrafo y maestro Rodolfo Franco (1889-1954)» (Roca, 2016, p. 13). Este tono de nostalgia y convencimiento de la promoción de una historia oficial argentina acompaña toda la narrativa del libro. Dividido en seis capítulos, un epílogo de comentarios de alumnos de Franco y una cronología de eventos, Roca recupera sucesos históricos del país constantemente para suplir los vacíos propios de una reconstrucción biográfica. Esta conjunción de datos, aunque unos más anecdóticos que otros, le permiten reposicionar la figura de Rodolfo Franco como una personalidad destacada del panorama artístico nacional durante la primera mitad del siglo XX.

Como en una novela histórica, Roca combina los sucesos del inicio de la vida del escenógrafo junto con algunos hechos sociopolíticos destacables de la ciudad porteña. Rodolfo Franco nace en el seno de una familia pudiente, oriunda de la Recoleta, encabezada por el ingeniero Juan Antonio Franco Raffo y Paula Acha Ezcurra. Crece en una Buenos Aires marcada por la incesante búsqueda de un posicionamiento del arte nacional. Por ejemplo, a pesar de la naciente deuda pública de Juárez Celman, se ordena la construcción del nuevo Teatro Colón en 1887 a cargo del arquitecto Tamburini como parte del importante movimiento artístico de la ciudad. También, hacia 1892, el cervecero alemán Emilio Bieckert encarga la construcción del Teatro Odeón, del que luego Franco sería director escenográfico desde 1937 hasta su muerte. En 1896 el Museo Nacional de Bellas Artes abre sus puertas en la galería comercial de Bon Marché de la mano del entonces director Eduardo Schiaffino. En el mismo espacio, Fausto Eliseo Coppini (1870-1945) instala su Taller del Bon Marché, donde Rodolfo Franco inicia sus estudios de dibujo y pintura en 1901. Interesado desde niño en las artes visuales, se opone a la sugerencia de su padre de estudiar arquitectura y consigue ser pensionado por su familia para ir 
1 Atilio Chiappori, crítico del diario $L a$ Nación, destaca: «Entre los pintores de su generación, es, quizás, el mejor dotado intelectualmente, para realizar una obra: Rodolfo Franco conoce todos los secretos de la paleta, conoce los recursos raros. Nadie podría enseñarle más» (Chiappori en Roca, 2016, p. 70)

2 El grabado ocupa un lugar central en su producción tanto artística como teórica, especialmente hacia el final de su vida. En 1915 realiza grabados sobre la noche sevillana, celebradas por la crítica argentina y española. Asimismo, toma los cargos de Profesor de Grabado en el Instituto de Argentino de Artes Gráficas (1931-1938) y Profesor de Pintura, Grabado y Dibujo en la Escuela de Bellas Artes Pueyrredón (1941 1954). Realiza, también, varias conferencias sobre historia del grabado. Su proyecto final inconcluso consiste en la realización de aguafuertes del Quijote. a estudiar a París en 1906. Obtiene allí un éxito inmediato entre París y España, promovido por su particular uso del color. ${ }^{1}$ Inicia sus estudios parisinos en la Academia Grande Chaumiére, donde aprende diseño y decoración con Maximilen Hiolle (1843-1938) y grabado ${ }^{2}$ con Edouard León Cortés (1882-1969). Pero se debe destacar su inscripción a la Academia Vitti, donde estudia pintura en el taller de Hermen Anglada Camarasa (1871-1959), pintor pionero antiacadémico que nuclearía a varios artistas argentinos en París. Camarasa descubre los trabajos de Franco como valiosos y le organiza una gira por varias galerías europeas, incluyendo la Academia de Londres donde termina por consagrarse como pintor profesional. Al respecto, en el periódico El Tiempo, en Buenos Aires en 1909 se enuncia:

[...] triunfos tan significativos como estos, quiere decir que la Argentina comienza a producir algo más que lana y maíz, que el ambiente rigurosamente práctico poco favorable a las manifestaciones intelectuales se extiende en el sentido de favorecer las obras del espíritu. [...] Por eso es que tributamos nuestro aplauso a artistas sinceros y talentosos como Franco que en Europa están empeñados en conseguir un puesto de honor para el naciente arte argentino (en Roca, 2016, p. 57).

La señalada intencionalidad de posicionar un arte nacional acompañará a Franco durante toda su producción artístico-escénica, aunque siempre influenciada por la formación y las teorías europeas, como se señalará más adelante.

En París, a través de Anglada Camarasa, descubre los Ballets Rusos de Sergei Diaghilev, que contaban con escenografía y vestuarios de Alexander Benois, Natacha Goncharova y León Bakst. Estos acontecimientos teatrales serían los gestores de la afición de Franco por el teatro, deslumbrado por la desmaterialización del espacio escénico a partir del uso del color y la perspectiva. También fomenta su interés por lo escénico al presenciar las obras de Jacques Rouché en el Teatro del Arte, Director de la Ópera de París desde 1914. Para Franco el trabajo de Rouché tenía como principal mérito «alejar el teatro de los fines comerciales y hacer de él un lugar de cultura, de estudio, de reconstrucción artística con sus obras líricas y poéticas que presentó con arte y sencillez deliciosa» (Franco en Roca, 2016, p. 62). Los modos de gestión y de creación teatral de los mencionados serían, para Franco, un sólido antecedente que sabrá luego replicar.

En 1918, desalentado por la Gran Guerra, regresa a la Argentina. Es muy bien recibido por el ambiente artístico y retoma su participación en Salones Nacionales y en la cultura porteña. Así es que en el tercer capítulo, «Afirmar lo propio (1918-1924)», Cora Roca finalmente puede explayarse sobre la 
prolífica carrera escenográfica de Rodolfo Franco. En 1922 asume la presidencia Marcelo T. de Alvear, quien está casado con Regina Pacini, una cantante italiana de renombre mundial. Entre las obras de beneficencia de la Primera Dama se incluye la creación de la Casa del Teatro, aún hoy en funcionamiento como albergue para artistas sin apoyo económico. También inauguran, en 1924, el Conservatorio Nacional de Música y Declamación, como otra de las fuertes apuestas al fomento de las artes escénicas. Gracias a este tipo de posturas por parte del matrimonio presidencial, la actividad teatral porteña se multiplica: se inauguran más de treinta salas y numerosas cantidades de compañías nacionales. Ernesto de la Cárcova finaliza la construcción de la Escuela de Bellas Artes y convoca a Rodolfo Franco como maestro de pintura. Finalmente, a través de Martín San Noel, es nombrado director escenográfico del Teatro Colón. De tradición italiana, en el Teatro solían presentarse costosos espectáculos extranjeros, franceses o alemanes, de limitado repertorio a óperas u otros géneros musicales. El cuerpo técnico y artístico era mayoritariamente italiano, siempre concesionado por familias y empresas aristócratas. Tras tomar el mando Rodolfo Franco en 1924, se publica en Buenos Aires en el diario El Telégrafo en 1929 una nota titulada «Rodolfo Franco ha argentinizado el Colón». En ella se destaca:

[Quienes trabajaban en el Colón] eran siempre italianos [por lo cual] la admisión de elementos italianos llevaba implícito el rechazo sistemático de todo elemento argentino, salvo caso de absoluta necesidad. Franco entró al taller e inició una obra, como decimos lenta pero segura de reivindicación de nuestro gran teatro para nuestra confiada nación; se dio a argentinizar el Colón (El Telégrafo en Roca, 2016, p. 131).

Parte de esto guarda relación con sus intenciones de cultivar lo propio, priorizando la producción en ámbitos locales. Al fundar el primer taller de escenografía argentina, se asegura que las decoraciones y los vestuarios de los espectáculos a presentar se produzcan el país. De esta manera, no solo suprime los gastos de compras europeas, sino que también fomenta sus intenciones de afirmar lo argentino: forma personal local en sus equipos, cuerpos estables de origen nacional y obras escenográficas. Con esto también se inicia como docente y replica la experiencia en el viejo Teatro Argentino de La Plata. En 1924 funda allí la carrera de Escenografía que, ocho años más tarde, se incorpora a la Escuela Superior de Bellas Artes de la Universidad Nacional de La Plata.

En la misma línea de promoción de una producción teatral local, entre 1925 y 1931 continúa al mando técnico del Teatro Colón. Entre las vastas programaciones, que incluían hasta treinta obras por temporada, Franco se encarga de la producción de la primera 
ópera argentina, Tabaré (1925), basada en el poema de Zorrilla de San Martín con música de Alfredo Schiuma. Le sigue Ollantay (1926), de Víctor Mercante y Constantino Gaito, junto con El Matrero (1929), de Felipe Boero, considerada la más representativa del nacionalismo artístico. Influenciado fuertemente por los Ballets Rusos de Diaghilev y Bakst, Franco produce desde el convencimiento de necesidad de una renovación teatral. Al generar los decorados y escenarios en su propio taller, pasa de estéticas más bien realistas a otras sugestivas, e innova y delimita una función, tal y como lo señalaría su alumno y discípulo Saulo Benavente:

Hasta la incorporación de Rodolfo Franco, la escenografía en la Argentina se encontraba en el campo del que la escenografía europea no había sido hasta fines del siglo pasado: el de las decoraciones naturalista consistentes en reproducciones, bien convencionales en la casi totalidad de los casos, de un determinado lugar geográfico. [...] La escenografía alcanza personalidad con Rodolfo Franco, uno de los primeros escenógrafos con visión total e integral, haciendo del escenógrafo el responsable de todo lo visualmente expresivo, es el que tiene la última palabra en los colores, en la arquitectura, en el espacio (Benavente en Roca, 2016, p. 151).

Se destaca, entonces, la búsqueda de Franco de un criterio estético local, a pesar de las precarias condiciones técnicas del teatro del momento. Determina, con su accionar, el papel del escenógrafo a la vez que funda una escuela y diversas experiencias estéticas que resultan innovadoras y celebradas. Sin embargo, en pleno auge de su producción, en 1931 renuncia a su cargo como director técnico del Teatro Colón, desalentado por la realidad política del período. A partir de ese momento continúa su labor artística desde 1937 como director escenográfico del Teatro Odeón y se dedica a teorizar sobre la escenografía como acción artística. Lo que sigue en su producción se instalará en la creación de fundamentos teóricos y en la realización de escenografías de compañías españolas radicadas en la Argentina.

\section{Escritos: teoría y escuela europea}

La producción escenográfica de Rodolfo Franco se ve acompañada de estudios históricos y teóricos que publica en diversas revistas y conferencias de alcance nacional. En Rodolfo Franco: escritos sobre arte y escenografía (2018), Cora Roca reúne algunos de estos escritos en orden de tradición historiográfica. Es decir que no los presenta según su año de publicación, sino respetando los cánones de una línea temporal oficial: separa oriente y occidente y comienza en Grecia Antigua para terminar 
3 En el prefacio insiste: «Lamentablemente, la mayoría de sus textos se han perdido en el olvido a causa de la obstinada costumbre que tenemos los argentinos de no valorar lo propio» (Roca, 2018, p. 14). en el siglo XVIII europeo. Cabe destacar que, en esta conjunción de textos, no se presentan historias o teorías teatrales que hayan sido gestadas en Argentina. En su lugar, Cora Roca divide el libro en dos apartados, "Escritos sobre arte" y "Escritos sobre escenografía», $y$, de este modo, convierte el texto en una llana reunión de fuentes de Rodolfo Franco. Nuevamente se posiciona desde la nostalgia oficialista de una figura perdida en la historia nacional ${ }^{3}$ y transcribe las reflexiones del escenógrafo, fuertemente marcadas por su formación europea. Así, por ejemplo, Roca retoma las conferencias de Franco sobre la historia del grabado en las grandes potencias europeas y las exhaustivas investigaciones sobre el teatro en las mismas. Es un valioso documento sitúa la producción de Franco como voz legitimada en el campo de las artes nacionales por su conocimiento de las prácticas históricas oficiales. Sin embargo, como ya se dijo, es notable la falta de intención de producir una historia del teatro argentino por parte de Franco. Presentado y considerado como el primer escenógrafo con preocupación por una producción local, no se rescatan en su hacer escritos sobre una valorización histórica de la misma.

Rodolfo Franco forma parte activa del campo teatral porteño en una época de enorme producción local: el nacimiento y la consolidación de los sainetes y grotescos criollos. Este período, entre 1910 y 1930, ha sido revalorizado por la historiografía teatral más revisionista. Al respecto, Jorge Dubatti (2012) reivindica este período denostado por ser posterior a la nombrada Época de Oro (entre 1900 y 1910) y por ser entendido como un momento de producción industrial en el teatro. Si bien Rodolfo Franco no perteneció plenamente al campo del teatro comercial, estuvo al tanto e incluso valorizó la producción nacional del momento:

\footnotetext{
Uno de mis proyectos más acariciados es incorporar mi labor a la escena nacional, porque las obras criollas ofrecen al artista un amplio horizonte para su fantasía decorativa. [...] Así, pues, todos los pintores argentinos dedicados a la especialidad teatral, debemos poner nuestros pinceles al servicio del mejoramiento de esa hermosa realidad que ya es la escena nacional (Roca, 2016, p. 197).
}

Por tanto, es destacable que la selección de fuentes a publicar por parte de Roca continúen en la línea de una valorización del teatro europeo antes que el nacional. Es probable que esto se relacione con rastros historiográficos teatrales tendientes a comparar los procesos argentinos con los anteriores. Esta comprensión idealizante de lo europeo y desmedro de lo local podría tener influencia en la producción teórico-histórica de 
Franco y la selección de Roca. Se destaca un caso abordado por Dubatti como un aporte a lo señalado:

Entre 1910 y 1930 el rechazo a la situación del teatro porteño es generalizado. [Como caso ejemplar se destaca] la encuesta que publica el diario La Crítica entre el 26 de julio y el 11 de agosto de 1924, en la que quince personalidades destacadas de diferentes disciplinas responden a la pregunta contundente «¿Por qué es verdaderamente malo el teatro nacional?». [Entre las respuestas concluyen] que la orientación mercantilista aleja cada vez más de la escena al autor que no es, al mismo tiempo, un excelente "productor», como se dice en el lenguaje comercial. [Finalmente,] los encuestados oponen el teatro comercial a un «teatro de arte» (Dubatti, 2012, pp. 20-21).

Si bien, como ya se dijo, Franco no pertenecía al nombrado teatro comercial, sí estaba ocupado en cultivar lo nacional en el teatro, por lo cual se convierte en un gran ausente en sus escritos la historia de la producción local.

Por otro lado, se debe destacar que, entre los textos seleccionados, solo uno no tiene intenciones de historizar, sino que teoriza acerca de la enseñanza de la escenografía en el país. Se trata del texto «La acción del arte en la preparación de los estudiantes de Bellas Artes» de 1937 (Roca, 2018), en el que Franco alienta a sus estudiantes a la disciplina artística. Así, considera que el bagaje cultural de cada alumno es importante y que su preparación técnica será lo que le permita abordar espiritualmente la obra. Se apoya en los atribuidos grandes pintores del Renacimiento para, finalmente, adherir a los tradicionales conceptos de equilibrio, proporción y armonía. Lo anterior resulta llamativo, pues su obra plástica no responde estrictamente a estos preceptos. Asimismo, al ser el único texto del libro sobre teoría artística, convierte en ausente su propia comprensión de la disciplina escenográfica que sí se hace presente, aunque tímidamente, en su biografía. Por ejemplo, Franco asume la necesidad de consolidar la cultura nacional a partir de comprender que el teatro «debe ser reteatralizado, lo que significa que no puede considerarse desvinculado de toda idea puramente teatral. [...] El teatro deber ser una estilización de la vida» (Roca, 2016, p. 225). Existe, entonces, entre los escritos de Franco una producción teórica apoyada por aquellas ideas clásicas señaladas anteriormente:

A los artistas plásticos nos corresponde la misión de corporizar el teatro, sirviendo el texto del creador literario con una creación decorativa, mediante planos, colores y luces, cuyos conceptos técnicos deben ponerse de manifiesto para componer un ambiente. [...] Hay pintores que han ensayado la escenografía sin lograr realizarla en el 
exacto sentido, porque no tienen idea de la composición y del equilibrio de las masas que es lo fundamental en ella (Roca, 2016, p. 243).

Se destacan, finalmente, dos grandes puntos en los libros de Cora Roca. El primero responde a una valiosa reconstrucción de quien fue fundador de las primeras prácticas escenográficas nacionales oficiales. Reivindica, con su trabajo, la vida y obra de un personaje no abordado, en términos de profundización, por la historiografía teatral argentina. El segundo punto a destacar es el perfil más bien tradicionalista de la autora, que no le habría permitido ahondar en el verdadero aspecto nacional de la obra de Franco. Existiría, como se arriesgó, una brecha entre sus intenciones nacionalistas de creación y los escritos publicados, tanto de selección como de producción europeizante. Es por eso que la lectura de ambos libros de Cora Roca debería considerarse complementaria para delinear un panorama general de la producción teatral nacional durante las décadas de 1920 a 1950. Esto permitirá entender la inscripción de Rodolfo Franco como una figura central, que realizó los caminos esperables para la época y que supo posicionar la escenografía argentina a partir de generar espacios de producción locales.

\section{Referencias}

Dubatti, J. (2012). Cien años de teatro argentino. Buenos Aires, Argentina: Biblos, Fundación OSDE.

Roca, C. (2016). Rodolfo Franco: el fundador de la escenografía argentina. Buenos Aires, Argentina: Eudeba.

Roca, C. (2018). Rodolfo Franco: escritos sobre arte y escenografía. Buenos Aires, Argentina: Eudeba. 